\title{
US versus Taiwan Healthcare System Reforms: What Can India Learn from Them?
}

\author{
Ajit Kumar'1, Sanjeev Maskara ${ }^{2}$ \\ ${ }^{1}$ Goa Institute of Management, Ribandar, India \\ ${ }^{2}$ The Practice PLC, Amersham, UK \\ Email: ajitmaskara@gmail.com, sanjeevmaskara@gmail.com
}

Received 6 October 2015; accepted 27 October 2015; published 30 October 2015

Copyright $(2015$ by authors and Scientific Research Publishing Inc.

This work is licensed under the Creative Commons Attribution International License (CC BY). http://creativecommons.org/licenses/by/4.0/

(c) () Op Open Access

\section{Abstract}

India has been famous for producing excellent clinicians who have served the entire world. Moreover, India has been one of the medical tourism destinations for international patients. Yet, unfortunately, healthcare facilities and resources for Indian citizen are not up to the standard compared to other countries. In recent years, the Indian healthcare system has received wide attention by the various stakeholders, such as patients, healthcare providers, health insurance companies, Information and Communication Technology companies, the government, and investors. The government of India has taken a number of initiatives in order to streamline the healthcare system of India. As many others have reformed their healthcare system, it is good to learn from their success and failure. In this paper, we discuss healthcare reforms in the USA and Taiwan. We find that, despite a number of healthcare reforms, the USA is somewhat struggling, whereas Taiwan is relatively successful in streamlining their healthcare system. Also, we explore a possible reason (Optimizing Big Coefficient or New Reality theory) for this gap. Afterwards, we highlight ongoing healthcare reform in India, including what India can learn from the USA and Taiwan.

\section{Keywords}

Big Coefficient, New Reality, Healthcare, USA, Taiwan, India

\section{Introduction}

This world needs a radically different healthcare system [1] [2]. A big and sustainable change in healthcare is being discussed at various national and international forums all over the world [3] [4]. Many countries, including developed, developing, and underdeveloped, have been trying to ensure high quality and have easily accessible healthcare facilities for their citizens through various healthcare reforms [5] [6]. As a result, the healthcare 
cost has been continuously rising [7]. Many other factors, such as the longevity of human life, the increasing proportion of older adults, technological advancement, increasing burden of chronic diseases, have further contributed to the overall healthcare cost [8]-[11]. Nowadays, providing quality healthcare with easy access to medical facilities at an affordable price is a grand challenge for almost all countries.

Many countries around the globe have used a variety of tools, techniques, and policies, such as (1) Information and Communication Technologies (ICT) to provide administrative and clinical support; (2) a range of management techniques to provide operational efficiency in the healthcare system; and (3) healthcare acts and policies to ensure healthcare insurance and equal access to healthcare facility for all [12]-[14]. The effects of all these efforts are normally assessed against three metrics—healthcare cost, quality, and accessibility [11]. These metrics are interdependent and interrelated in such a way that change in one affects others [15]. Despite serious endeavors, most of the countries are facing a serious challenge in terms of cost, quality, and accessibility [16]. For instance, the USA is quite worried about their healthcare cost, which is $14 \%$ of their Gross Domestic Product (GDP) [17]. Taiwan, which has received worldwide appreciation, is fine with cost and accessibility; however, they are worried about declining quality and long-term sustainability of their healthcare system. Likewise, India is relatively fine with overall healthcare cost; however, healthcare quality and accessibility are two areas that need serious improvements.

In 1990, the economy of India grew tremendously after the Indian government promotion for the globalization, liberalization, and privatization [18]. India has made a profound growth in sectors, such as agriculture, textile, construction, telecommunication, information technology, banking, education, and finance, and the same is expected in the healthcare sector [19] [20]. India has been famous for producing excellent clinicians who have been serving across the globe. India is one of the medical tourism destinations for international patients. However, unfortunately, healthcare facilities and resource for Indian citizens have been not up to the mark compared to other nations [21]. Therefore, in recent years, the Indian healthcare sector has received a wide attention by its stakeholders, such as patients, healthcare providers, health insurance companies, Information and Communication Technology companies, government, and investors. The Government of India has adopted many initiatives to improve its healthcare system. The Indian government has taken a firm stand on using Information and Communication Technologies (ICT). For instance, in 2003, the Ministry of Communication and Information Technology, India recommended a framework for healthcare IT infrastructure that included Telemedicine's guidelines, standards, and practices. The Ministry of Health and Family Welfare (MoHFW), India set up a task force in 2005 to look at the issues and standards related to Electronic Health Record (EHR) [22]. In April 2013, the MoHFW released EHR Standard Version 5 to encourage health information exchange among its stakeholders. Furthermore, increasing number of health insurance companies, demand for quality healthcare, and increasing use of ICT in medical institutions are a few recent initiatives in Indian healthcare system. However, with all these initiatives, we are unintentionally following the same route that has not led encouraging success to countries that already crossed it.

In this situation, we argue that India needs to study the healthcare system around the world. Since many other countries have reformed their healthcare system, it is good to learn from their success and failure stories. As a step towards this goal, we study the healthcare reforms of the USA and Taiwan, their success and failure stories, and the theoretical explanation behind their success and/or failure. Finally, we have highlighted the ongoing healthcare reforms in India, including what India can learn from the USA and Taiwan.

\section{US Healthcare System}

The historical facts reveal that the USA has gone through a massive healthcare reform in the last five decades. The initial emphasis was on the coverage of healthcare risks, high-quality services, and easy accessibility. Various healthcare reforms, such as Medicare and Medicaid (1965), Consolidated Omnibus Budget Reconciliation Act (COBRA, 1985), State Children's Health Insurance Program (SCHIP, 1997), and Affordable Care Act (2010), were made at the Federal and State level, which could not bring much success towards the original goals. The healthcare cost kept escalating. Today, more than 45 million Americans are uninsured. Many people have to face bankruptcies because of illnesses. The health insurance companies spend 20 to 30 percent of their expenditure to meet the administrative cost. The USA kept reforming their healthcare system in a piecemeal manner. The initial focal point was to cover health risks of the individual. When healthcare costs escalated due to the longevity of human life, technological advancement, and demand for quality care; various management prin 
ciples based healthcare plans, such as Preferred Provider Organizations (PPO), Points of Service (POS), Health Maintenance Organizations (HMO), and Consumer-Driven Healthcare (CDH) mushroomed all over the United States. These plans were framed in such a way that they should control the cost and keep transferring "healthcare risk” among all—patient, providers, employers, government, and insurance companies (Figure 1). This tendency of risk transfer has distorted the original concept, meaning, and purpose of the health insurance. Health insurance is insurance against the risk of incurring medical expenses among individuals. By estimating the overall risk of health care and health system expenses, among a targeted group, an insurer can develop a routine finance structure, such as a monthly premium or payroll tax, to ensure that money is available to pay for the health care benefits specified in the insurance agreement. The benefit is administered by a central organization, such as a government agency, private business, or not-for-profit entity (Wikipedia). However, private health insurance players in the US tried to control the cost for making their profits and avoiding the potential misuse of the health insurance by other stakeholders, such as overbilling by healthcare providers, excessive use of healthcare facilities by patients and so on. This motivated them to transfer a part of their risk to other stakeholders. As insurance companies are collecting the premium, ideally, they are supposed to cover the entire risk.

In addition, the healthcare stakeholders in the USA were somewhat focused in fine-tuning the big coefficients $\mathrm{A}, \mathrm{B}$, and so on, which are evinced in the following equation and explained in the next paragraph

$$
\text { Healthcare Cost }(\text { Clinical, Administrative, } \ldots)=A \times \text { Clinical }+B \times \text { Administrative }+\ldots C
$$

The stakeholders have often controlled the healthcare cost by optimizing the coefficients $(A, B \ldots)$ using various managerial and technical skills [23]. In addition, various healthcare reforms, such as Medicare, Medicaid, COBRA, SCHIP, HMO Act, HIPAA, and Affordable Care Act, exerted pressure on tweaking the coefficients A, B, and so on (Equation (1)). For example, government-sponsored programs, such as Medicare, Medicaid, SCHIP,

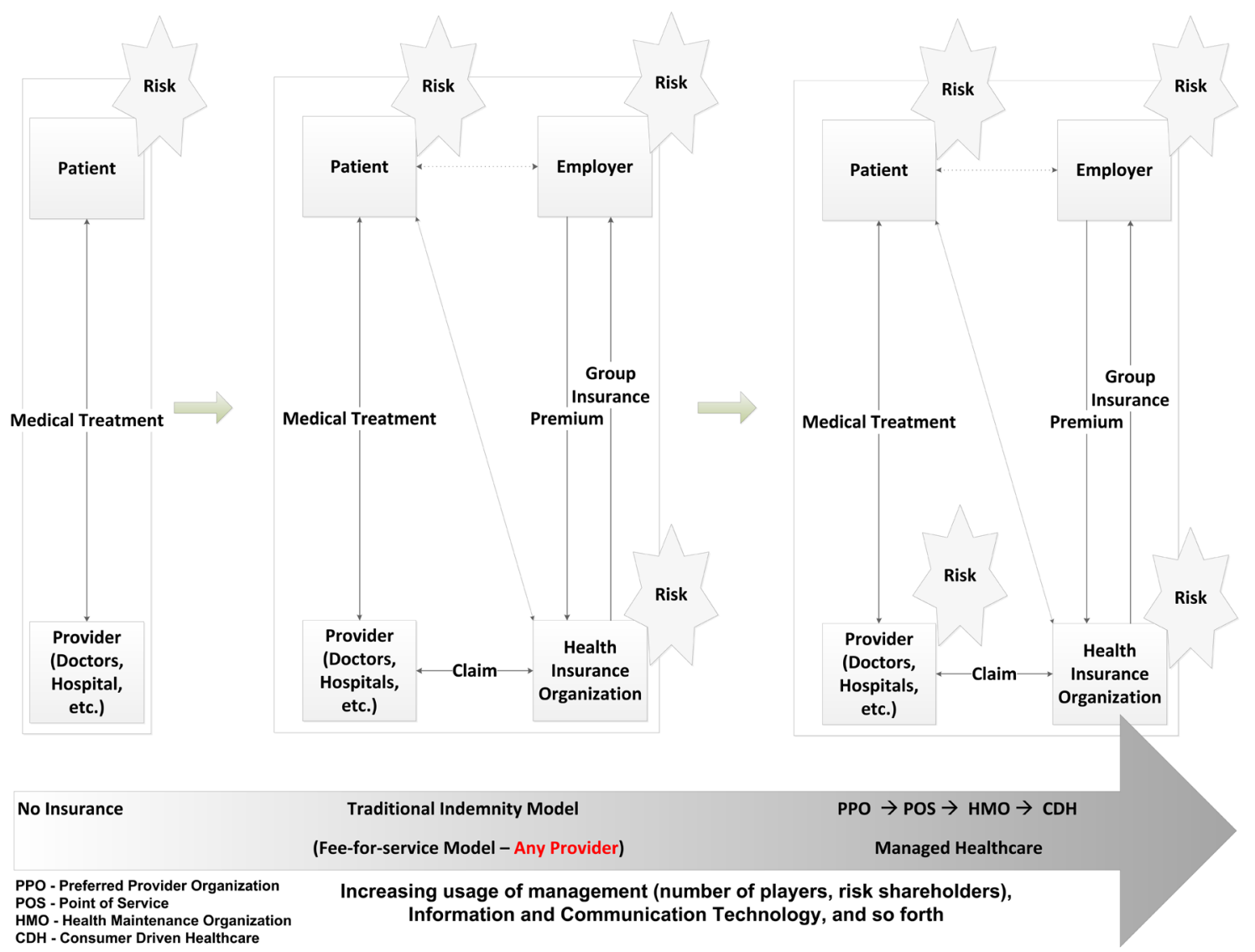

Figure 1. Evolution of the US healthcare. 
and COBRA, were implemented to provide increased and continued accessibility to older adults, poor, children, and employees. Managed care (HMO, POS, and PPO) and consumer-driven healthcare tried to optimize the cost of care by sharing healthcare risks among various stakeholders. Likewise, HIPAA and Affordable Care Act emphasized deploying information and communication technologies to the maximum. All these efforts kept tweaking the coefficients and unintentionally forgot an important basic fact-as tweaking coefficients have limitations; it is a time to think about new realities.

\section{Healthcare System in Taiwan}

Taiwan has a compulsory healthcare system called the National Health Insurance (NHI). In 1995, the NHI program was launched to provide universal healthcare and streamline the previous healthcare system. All residents, including foreign residents, who have lived in Taiwan for at least four months, are compulsorily required to enroll in the NHI program of Taiwan. To date, $99.6 \%$ of 23 million people, including half-million foreigners, are covered by the NHI program [24]. Presently, the NHI is the most-favored social policy in Taiwan, which enjoys an increasing public satisfaction rate from $68 \%$ in 2001 to $87 \%$ in 2010. The high life expectancy of people of Taiwan (79.16-year in 2011), equal access to a broad range of medical services, low premiums and copayments, lower healthcare expenditures, low administrative costs (1.5 percent of the total healthcare cost), and almost zero waiting time is the major achievements of NHI [25].

First, people of Taiwan perceived healthcare as a social issue and took the entire healthcare risks of all people of Taiwan, including foreign residents (Figure 2). The one-time healthcare reform in 1995 yielded fewer numbers of stakeholders (patients, providers, and government), centralized control of the government, and healthcare as a social responsibility [25].

Second, Taiwan's healthcare system underwent only one reform, by assuming the concept of new reality (Figure 2). In the new reality approach, they made an effort to understand how other advanced countries have funded and organized their healthcare system. The healthcare systems of six high-income countries-United

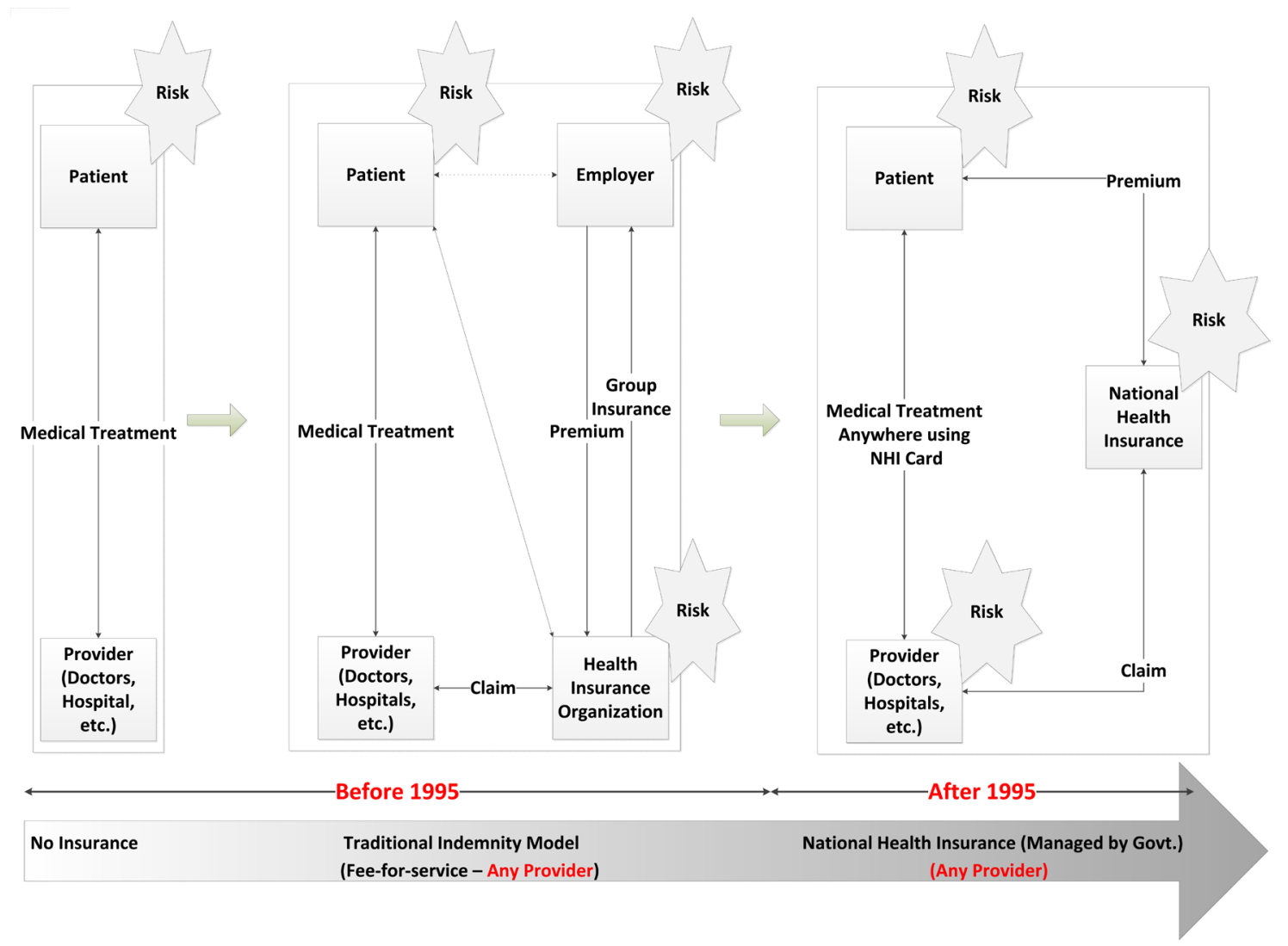

Figure 2. Evolution of the healthcare in Taiwan. 
States, UK, Germany, France, Canada, and Japan-were understood. They tried to learn from success and failure stories of these countries before embarking a health insurance plan for Taiwan [26]. The USA has been always a leader and a great advocate of the new reality; however, they remained somewhat busy in optimizing the big coefficients of healthcare. Moreover, the new reality in the US healthcare system is yet to be seen. Taiwan and the USA in healthcare reforms set examples for the entire world that, unlike other systems, the healthcare system is different (social, universal, complex adaptive), and any reform should be performed with utmost care [27]-[29].

\section{Indian Healthcare System}

India has a universal healthcare system run by the constituent states and territories of India [30]. The Constitution of India instructs every state to raise the level of nutrition, the standard of living, and public health, as among its primary duties. The Indian Parliament endorsed the National Health Policy in 1983 and updated in 2002. India has taken measures, such as telemedicine, and mobile health to improve healthcare accessibility and quality. India has been using a hub-and-spoke design with hub hospitals located in the main cities and spoke hospitals in rural areas. This strategy concentrates the best equipment and expertise within the hub, with telecommunication links that allow hub specialists to serve spoke patients remotely [31].

Government of India has taken some initiatives to propose standardization and health information exchange. In 2003, Ministry of Communication and Information Technology recommended a framework for IT infrastructure for healthcare, including guidelines and standard for practicing telemedicine in India. India has made a tremendous progress in telemedicine [32] [33]. The Ministry of Health and Family Welfare (MoHFW) India sets up a task force in 2005 to look at the issues and standards related to EHR. In April 2013, MoHFW released EHR standard version 5 to encourage health information exchange [34].

\section{What Can India Learn from the USA and Taiwan?}

We find that, despite a number of healthcare reforms, the USA is somewhat struggling, whereas Taiwan is a relatively successful in streamlining their healthcare system. Taiwan spends about 6.9 percent of its Gross Domestic Product (GDP) on healthcare, compared with 18 percent spent in the United States of America (USD 7500 per person annually) (Table 1) [24] [35]. Despite a wealth of skilled healthcare providers, and medical technological advancement, a significant portion of the US population has limited access to healthcare services (Table 1).

In summary, India can learn several lessons from the USA and Taiwan. For instance, India should study other's system before embarking upon its system. Likewise, India also has to think if it wants-tweaking coefficients similar to the US, or the new reality like Taiwan, or both (Figure 3). Tweaking the coefficients makes use of management and technology to control the cost of healthcare while maintaining quality of care. This coefficient optimization mainly focuses on cost-cutting, which has been used in the US because of ever increasing healthcare cost. Whereas, new reality is to come up with some innovative solutions with new vision and goal. As Indian perception towards healthcare is very different than the US, and fortunately, healthcare cost is not a big issue (3\% of GDP) for the Indian government; India should take a unique approach based on its need, with a right mix of coefficient optimization and new reality.

Table 1. Salient features of the US and Taiwan healthcare systems.

\begin{tabular}{ccc}
\hline Salient Features & US Healthcare System & Taiwan Healthcare System \\
GDP & $18 \%$ & $6.9 \%$ \\
Public Satisfaction & $67 \%$ & $7 \%$ \\
Life Expectancy & 78.74 years & 79.16 years \\
Uninsured Population & $13.4 \%$ & $0.4 \%$ \\
Administrative Cost & Optimizing big coefficients & Looking for the new reality \\
Approach of Health Reform & A mix of public and private insurance & Universal insurance \\
Insurance Model & Restricted access & Full access (any provider, anytime) \\
Access to Healthcare Provider &
\end{tabular}




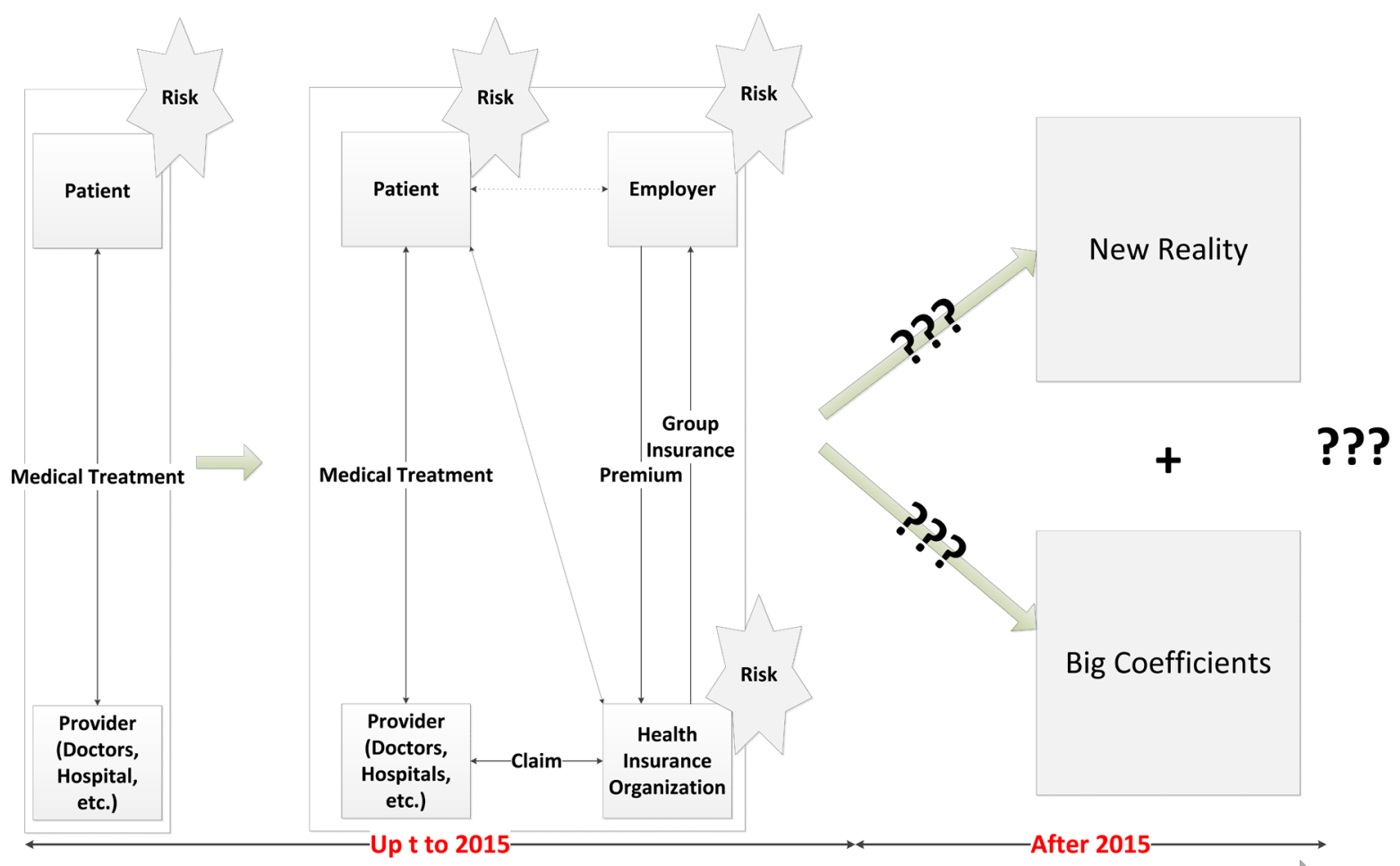

No Insurance (87\% of population)

Traditional Indemnity Model

(17\% of population is covered - source Hindu Dec 2014) (Fee-for-Service - Any Provider)

\section{Figure 3. Big coefficients, new reality, or both.}

Nowadays, health insurance companies are mushrooming all over the India to manage healthcare risk of Indian people. Indian citizens have started to look for quality healthcare. Some private medical institutions have also begun using ICT for their administrative and fiscal revenue purposes. With all these initiatives in India, we are, unintentionally, following the same route that has not led that many successes to countries that already cross it. Therefore, India needs to step back, learn from others, and then move forward to achieve its visionary goal—quality and guaranteed healthcare for all Indians.

\section{References}

[1] Ferlie, E.B. and Shortell, S.M. (2001) Improving the Quality of Health Care in the United Kingdom and the United States: A Framework for Change. The Milbank Quarterly, 79, 281. http://dx.doi.org/10.1111/1468-0009.00206

[2] Wilsford, D. (1994) Path Dependency, or Why History Makes It Difficult But Not Impossible to Reform Health Care Systems in a Big Way. Journal of Public Policy, 14, 251-283. http://dx.doi.org/10.1017/S0143814X00007285

[3] World Health Organization (2000) The World Health Report 2000: Health Systems: Improving Performance. World Health Organization.

[4] Bate, P., Robert, G. and Bevan, H. (2004) The Next Phase of Healthcare Improvement: What Can We Learn from Social Movements? Quality and Safety in Health Care, 13, 62-66. http://dx.doi.org/10.1136/qshc.2003.006965

[5] Twaddle, A.C. (2002) Health Care Reform around the World. Greenwood Publishing Group, Santa Barbara.

[6] Tanner, M. (2008) The Grass Is Not Always Greener: A Look at National Health Care Systems around the World. Cato Policy Analysis Paper No. 613. http://dx.doi.org/10.2139/ssrn.1262978

[7] Paez, K.A., Zhao, L. and Hwang, W. (2009) Rising Out-of-Pocket Spending for Chronic Conditions: A Ten-Year Trend. Health Affairs, 28, 15-25. http://dx.doi.org/10.1377/hlthaff.28.1.15

[8] Rice, D.P. and Fineman, N. (2004) Economic Implications of Increased Longevity in the United States. Annual Review 
of Public Health, 25, 457-473. http://dx.doi.org/10.1146/annurev.publhealth.25.101802.123054

[9] Mascie-Taylor, C.N. and Karim, E. (2003) The Burden of Chronic Disease. Science, 302, 1921-1922. http://dx.doi.org/10.1126/science.1092488

[10] Altman, S.H. and Blendon, R. (1977) Medical Technology: The Culprit behind Health Care Costs? Proceedings of the 1977 Sun Valley Forum on National Health, Sun Valley, August 1977, 15-23.

[11] Weisbrod, B.A. (1991) The Health Care Quadrilemma: An Essay on Technological Change, Insurance, Quality of Care, and Cost Containment. Journal of Economic Literature, 29, 523-552.

[12] Gagnon, M.P., Légaré, F., Labrecque, M., Frémont, P., Pluye, P., Gagnon, J. and Gravel, K. (2009) Interventions for Promoting Information and Communication Technologies Adoption in Healthcare Professionals. Cochrane Database of Systematic Reviews, 1, Article ID: CD006093. http://dx.doi.org/10.1002/14651858.cd006093.pub2

[13] Jacobs, R., Smith, P.C. and Street, A. (2006) Measuring Efficiency in Health Care: Analytic Techniques and Health Policy. Cambridge University Press, Cambridge. http://dx.doi.org/10.1017/CBO9780511617492

[14] Mhatr, S.L. and Deber, R.B. (1992) From Equal Access to Health Care to Equitable Access to Health: A Review of Canadian Provincial Health Commissions and Reports. International Journal of Health Services, 22, 645-668. http://dx.doi.org/10.2190/UT6U-XDU0-VBQ6-K11E

[15] Sloan, F.A., Blumstein, J.F. and Perrin, J.M. (1988) Cost, Quality, and Access in Health Care: New Roles for Health Planning in a Competitive Environment. Jossey-Bass Publishers, San Francisco.

[16] Lesser, C.S. and Ginsburg, P.B. (2001) Back to the Future? New Cost and Access Challenges Emerge. Initial Findings from HSC’s Recent Site Visits. Issue Brief No. 35, Center for Studying Health System Change, Washington DC.

[17] Reinhardt, U.E., Hussey, P.S. and Anderson, G.F. (2004) US Health Care Spending in an International Context. Health Affairs, 23, 10-25. http://dx.doi.org/10.1377/hlthaff.23.3.10

[18] Budhwar, P. (2001) Doing Business in India. Thunderbird International Business Review, 43, 549-568. http://dx.doi.org/10.1002/tie.1013

[19] Krishna, P. and Mitra, D. (1998) Trade Liberalization, Market Discipline and Productivity Growth: New Evidence from India. Journal of Development Economics, 56, 447-462. http://dx.doi.org/10.1016/S0304-3878(98)00074-1

[20] Kohli, A. (2006) Politics of Economic Growth in India, 1980-2005: Part I: The 1980s. Economic and Political Weekly, 1251-1259.

[21] Bajpai, N. and Goyal, S. (2004) Primary Health Care in India: Coverage and Quality Issues. CGSD Working Paper No. 15.

[22] Kumar, A., Bhattacharya, I., Bhattacharya, J., Ramachandran, A., Maskara, S., Kung, W.M., et al. (2014) Deploying Cloud Computing to Implement Electronic Health Record in Indian Healthcare Settings. Open Journal of Mobile Computing and Cloud Computing, 1, 35-47.

[23] Page, S. (2013) The Big Coefficient vs. the New Reality.

[24] Chan, R. (2012) US Scholar Praises Taiwan Health Care System. Taiwan Today, 2012.

[25] Cheng, T.M. (2009) Lessons from Taiwan’s Universal National Health Insurance: A Conversation with Taiwan's Health Minister Ching-Chuan Yeh. Health Affairs, 28, 1035-1044. http://dx.doi.org/10.1377/hlthaff.28.4.1035

[26] Underwood, A. (2009) Health Care Abroad: Taiwan. The New York Times.

[27] Rouse, W.B. (2008) Health Care as a Complex Adaptive System: Implications for Design and Management. BridgeWashington-National Academy of Engineering, 38, 17.

[28] Begun, J.W., Zimmerman, B. and Dooley, K. (2003) Health Care Organizations as Complex Adaptive Systems. Advances in Health Care Organization Theory, 253, 288.

[29] Miller, J.H. and Page, S.E. (2009) Complex Adaptive Systems: An Introduction to Computational Models of Social Life. Princeton University Press, Princeton.

[30] Reddy, K.S., Patel, V., Jha, P., Paul, V.K., Kumar, A.S. and Dandona, L., Lancet India Group for Universal Healthcare (2011) Towards Achievement of Universal Health Care in India by 2020: A Call to Action. The Lancet, 377, 760-768. http://dx.doi.org/10.1016/S0140-6736(10)61960-5

[31] Govindarajan, V. and Ramamurti, R. (2013) Indian Hospitals Could Show US Hospitals How to Save Money without Cutting Quality. Washington Post, November 1, 2013.

[32] Mohandass, D. and Janet, J. (2013) A Segmentation Based Retrieval of Medical MRI Images in Telemedicine. Journal of Scientific \& Industrial Research, 72, 107-113.

[33] Bai, V.T. and Srivatsa, S.K. (2008) Design and Implementation of Mobile Telecardiac System. Journal of Scientific \& 
Industrial Research, 67, 1059-1063.

[34] GOI (2013) Recommendations on Electronic Medical Records Standards in India. MOHFW.

[35] Reinhardt, U. (2012) Taiwan's Progress on Health Care. The New York Times. 